\title{
Spironolactone dose-dependently alleviates the calcification of aortic rings cultured in hyperphosphatemic medium with or without hyperglycemia by suppressing phenotypic transition of VSMCs through downregulation of Pit-1
}

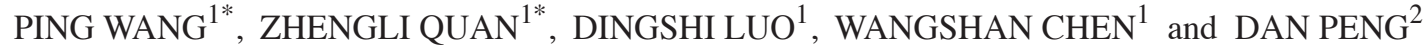 \\ Departments of ${ }^{1}$ Nephrology and ${ }^{2}$ Neonatology, The First People's Hospital of Jingmen, Jingmen, Hubei 448000, P.R. China
}

Received October 9, 2018; Accepted February 11, 2019

DOI: $10.3892 / \mathrm{mmr} .2019 .10039$

\begin{abstract}
Vascular calcification (VC) is highly prevalent in chronic kidney disease (CKD), especially in patients with end stage renal disease and is strongly associated with cardiovascular morbidity and mortality. Clinical observations have demonstrated that hyperphosphatemia and hyperglycemia can accelerate VC. Spironolactone (SPL) has been proven to improve cardiovascular outcomes in clinical trials and its protective effect on VC has been reported recently; however, the underlying mechanisms are not completely understood and require further investigation. Furthermore, the current CKD rat models that are used to research $\mathrm{VC}$ do not match well with the clinical characteristics of CKD patients. Aortic rings were obtained from male Sprague-Dawley rats, then cultured in different media with varying phosphorus and glucose concentrations to investigate the effects and the possible mechanisms, as well as the effective serum concentrations
\end{abstract}

Correspondence to: Dr Dan Peng, Department of Neonatology, The First People's Hospital of Jingmen, 168 Xiangshan Avenue, Jingmen, Hubei 448000, P.R. China

E-mail: 34298306@qq.com

*Contributed equally

Abbreviations: VC, vascular calcification; VSMC, vascular smooth muscle cell; SPL, Spironolactone; CKD, chronic kidney disease; ESRD, end-stage renal disease; AMC, arterial medial calcification; SM, smooth muscle; Runx2, Runt-related transcription factor 2; Cbf $\alpha 1$, core binding factor $\alpha-1$; Pi, inorganic phosphorus; $\mathrm{NaPi}$, sodium-dependent Pi; MR, mineralocorticoid receptor; NIH, National Institutes of Health; DMEM, Dulbecco's modified Eagle's medium; CNT, control group; HG, high glucose group; HPi, high phosphate group; HGHPi, high glucose and high phosphate group; LS, low SPL; MS, medium SPL; HS, high SPL; BCA, bicinchoninic acid; TBST, tris-buffered saline with Tween 20; DN, diabetic nephropathy

Key words: vascular calcification, vascular smooth muscle cell, hyperglycemia, hyperphosphatemia, type III sodium-dependent phosphate cotransporter- 1 , spironolactone of SPL, on VC and type III sodium-dependent phosphate cotransporter-1 (Pit-1) expression. SPL dose-dependently alleviated VC by suppressing the phenotypic transition of vascular smooth muscle cell (VSMCs) through downregulation of Pit-1 in a high phosphorus medium and even in a high phosphorus combined with high glucose medium. The combined effects of hyperglycemia and hyperphosphatemia on the calcification of aortic rings ex vivo were demonstrated. In conclusion to the best of our knowledge, this article is the first report on the effective serum concentrations of SPL capable of protecting VSMCs from calcification and provides the first experimental evidence for the combined effects of hyperglycemia and hyperphosphatemia on VC of aortic rings. Additionally, the Pit-1 protein level may be a novel index for evaluating the magnitude of $\mathrm{VC}$ in $\mathrm{CKD}$ patients.

\section{Introduction}

Vascular calcification (VC) is highly prevalent in patients with chronic kidney disease (CKD), especially those with end-stage renal disease (ESRD). It is strongly associated with cardiovascular morbidity and mortality (1-3), and may be a useful index for identifying CKD patients at high risk of death (4). Arterial medial calcification (AMC), in particular, is an important cause of decreased vascular compliance in aging, diabetes and CKD (5). In AMC, hydroxyapatite $\left[\mathrm{Ca}_{10}(\mathrm{PO} 4)_{6}(\mathrm{OH})_{2}\right]$ deposition in arterial media is considered significant to its development (6).

Accumulating evidence indicates that $\mathrm{VC}$ does not occur via a passive deposition of minerals, but rather an active cell-mediated process, which involves phenotypic transition of vascular smooth muscle cells (VSMCs) into osteoblast-like cells, apoptosis of VSMCs, loss of calcification inhibitors, matrix vesicle release and extracellular matrix degradation (7-9). The expression of VSMC differentiation marker genes, including smooth muscle $22 \alpha$ (SM22 $\alpha$ ) and smooth muscle $\alpha$-actin (SM $\alpha$-actin), is decreased during the smooth muscle cell phenotypic transition (10). Meanwhile, Runt-related transcription factor 2 (Runx2; also known as core binding factor $\alpha-1, \operatorname{cbf} \alpha-1)$, an important osteoblast-specific gene that regulates osteoblast and chondrocyte differentiation, is expressed in VC (11-13). 
Phosphate transport into cells, which is now considered crucial to VC, is primarily mediated by NaPi (sodium-dependent $\mathrm{Pi}$ ) cotransporters, of which there are 3 types. The inhibition of NaPi transporters would be a preferable method compared with oral phosphate binders to control serum Pi level in patients with CKD or undergoing dialysis (14). Type III sodium-dependent phosphate cotransporter-1 (Pit-1), is the predominant $\mathrm{NaPi}$ cotransporter in human VSMCs and is required for phosphate-induced calcification of human VSMCs, and is a major regulator of cellular differentiation programs involved in normal and pathological calcification (15). It is thought that high phosphorus activates Pit-1 of VSMCs to enter the cell, then induces the expression of osteochondrogenic differentiation gene (for instance, Runx2) which ultimately initiates vascular calcification $(15,16)$. However, the full mechanism of action of Pit-1 in VC remains clear.

Spironolactone (SPL), a mineralocorticoid receptor (MR) antagonist, has been identified to improve cardiovascular outcomes in clinical trials $(17,18)$. The suppression of MRs during the phenotypic changes in VSMCs, as well as during oxidative stress and fibrogenesis, by MR antagonists is considered beneficial for cardiovascular outcomes $(19,20)$. Wu et al (21) demonstrated that aldosterone was elevated in the calcified areas of the aortas of rats without renal failure, which indicated that aldosterone may take part in VC. The protective effects of SPL on VC in vitro and in vivo have been reported $(22,23)$. However, whether SPL can prevent the progression of $\mathrm{VC}$, the exact dose required and the mechanism by which SPL intervenes in the pathogenesis of VC in CKD are unclear (24).

To date, only two CKD rat models have been used to research VC: An adenine-induced CKD rat model and a partial nephrectomy (e.g. 5/6 nephrectomy) model. The adenine-induced CKD model is similar to chronic progressive tubulointerstitial nephritis (25). The partial nephrectomy model simply provides a model with a reduction in the number of nephrons present. It is known that most cases of CKD are a result of hypertension, diabetes and glomerular disease (26). Therefore, the two models have limitations and they are rarely encountered in clinical work.

The present study aimed to clarify the potential link between hyperglycemia and hyperphosphatemia in VC, and to investigate the mechanistic pathway and effective dose of SPL in $\mathrm{VC}$ in a novel experimental model that aimed at mimicking CKD in humans more closely.

\section{Materials and methods}

Ethics statement. Ethical approval was granted by the Ethical Committee of the First People's Hospital of Jingmen (Jingmen, China) and the study protocols conformed to the National institute of Health (NIH) guidelines for the care and use of laboratory animals.

Aortic tissue culture. A total of 29, 8-10-week-old male Sprague-Dawley rats (280-300 g) were purchased from the Hubei Provincial Center for Disease Control and Prevention (Wuhan, China). Following 1 week of acclimatization under specific pathogen-free conditions at $20 \pm 2^{\circ} \mathrm{C}$, with a relative humidity $50-70 \%$ and under a 12-h light/dark cycle and with free access to a standard diet and water, the rats were euthanized. The thoracic aortas of the rats were then isolated, cut into several 3-4 mm rings and cultured in Dulbecco's modified Eagle's medium (DMEM; HyClone; Logan, UT, USA) with $10 \%$ (v/v) fetal bovine serum (Hyclone), and 1\% streptomycin and penicillin. The aortic rings were maintained in $5 \%(\mathrm{v} / \mathrm{v})$ $\mathrm{CO}_{2}$ at $37^{\circ} \mathrm{C}$ in a humidified atmosphere and the medium was changed every 2 days. The DMEM contained $0.9 \mathrm{mM} \mathrm{PO}_{4}{ }^{3-}$ and 5.5 or $25 \mathrm{mM}$ glucose, with a pH of 7.2. $\mathrm{Na}_{2} \mathrm{HPO}_{4} \cdot 12 \mathrm{H}_{2} \mathrm{O}$, $\mathrm{NaH}_{2} \mathrm{PO}_{4} \cdot 2 \mathrm{H}_{2} \mathrm{O}$, glucose and/or SPL were added to the serum-supplemented DMEM to create various glucose and phosphate as well as SPL concentrations according to the experimental groups described below.

Aortic rings were divided into 10 groups $(n=9)$, grown in six-well plates and treated with the growth or calcifying media for 14 days. The groups were as follows: i) Control group (CNT), treated with normal glucose $(5.5 \mathrm{mM})$ and $\mathrm{Pi}$ (0.9 mM) without SPL; ii) high glucose group (HG), treated with high glucose $(30 \mathrm{mM})$ and normal Pi without SPL; iii) high phosphate group (HPi), treated with normal glucose and high Pi (2.5 mM) without SPL; iv) high glucose and high phosphate group (HGHPi), treated with high glucose and high Pi without SPL; v) HPi with low SPL (200 ng/ml) group (HPiLS); vi) HPi with medium SPL (1,000 ng/ml) group (HPiMS); vii) HPi with high SPL (5,000 ng/ml) group (HPiHS); viii) HGHPi with low SPL group (HGHPiLS); ix) HGHPi with medium SPL group (HGHPiMS); and x) HGHPi with high SPL group (HGHPiHS).

Quantification of VSMC calcification. Following being harvested and washed with $\mathrm{PBS}$, the aortic rings were treated with $0.6 \mathrm{~N} \mathrm{HCl}$ overnight at $4^{\circ} \mathrm{C}$. The $\mathrm{Ca}$ concentrations of the supernatants were determined by the o-cresolphthalein complexone method using a commercially available kit according to the manufacturer's protocol (Calcium Assay kit; Nanjing Jiancheng Bioengineering Institute, Nanjing, China). Ca concentrations were normalized to total cellular protein by the bicinchoninic acid (BCA) protein assay, for which BCA commercial reagents were purchased from Aspen Biotechnology (Wuhan, Hubei, China).

Reverse transcription-quantitative polymerase chain reaction (RT-qPCR). Total RNA was extracted using Trizol reagent (Invitrogen; Thermo Fisher Scientific, Inc., Waltham, MA, USA), according to the manufacturer's protocol. The complementary DNA was prepared by using a PrimeScript ${ }^{\mathrm{TM}}$ RT reagent kit with gDNA eraser according to the manufacturer's protocol (Takara Bio, Inc., Otsu, Japan). The temperature protocol of the RT was the following: $37^{\circ} \mathrm{C}$ for $15 \mathrm{~min}$ followed by $85^{\circ} \mathrm{C}$ for $15 \mathrm{sec}$. A SYBR ${ }^{\circledR}$ Premix Ex Taq ${ }^{\mathrm{TM}}$ reagent kit (Takara Bio, Inc.) was used for quantitative PCR on a StepOne ${ }^{\mathrm{TM}}$ Real-Time PCR system (Thermo Fisher Scientific, Inc.). The PCR conditions were as follows: $95^{\circ} \mathrm{C}$ initial denaturation for $1 \mathrm{~min}, 40$ cycles with $95^{\circ} \mathrm{C}$ for $15 \mathrm{sec}, 58^{\circ} \mathrm{C}$ for $20 \mathrm{sec}, 72^{\circ} \mathrm{C}$ for $45 \mathrm{sec}$. The program for analytic melting was followed by an increase in temperature from $60^{\circ} \mathrm{C}$ to $95^{\circ} \mathrm{C}$ with a $0.05^{\circ} \mathrm{C} / \mathrm{sec}$ ramp rate. Primers for Runx $2, \mathrm{SM} \alpha$-actin, SM22 $\alpha$ and GAPDH (internal reference) were purchased from Genecreate Bioengineering Co., Ltd. (Wuhan, China), and the sequences were: GAPDH, 5'-CGCTAACATCAAATGGGG 
TG-3' (forward), 5'-TTGCTGACAATCTTGAGGGAG-3' (reverse); Runx2, 5'-TACTCTGCCGAGCTACGAAATG-3' (forward), 5'-TGAAACTCTTGCCTCGTCCG-3' (reverse); SM22 $\alpha$, 5'-ATCCAAGCCAGTGAAGGTGC-3' (forward), 5'-ACTCCCTCTTATGCTCCTGGG-3' (reverse); SM $\alpha$-actin, 5'-GTGACGAGGACGAGACCACC-3' (forward), 5'-GGG TCAGGATACCTCGCTTG-3' (reverse). The specificity of the PCR procedure was confirmed by analysis of the melting curves. The relative expression levels of the target genes were determined by the $2^{-\Delta \Delta \mathrm{Cq}}$ method (27).

Western blotting. Following protein extraction using radioimmunoprecipitation assay lysis buffer (cat. no. as1004; Aspen Biotechnology), total protein concentration was quantified using the BCA commercial reagents. Protein samples $(40 \mu \mathrm{g})$ were separated by 8 or $10 \%$ SDS-PAGE and transferred onto polyvinylidene difluoride membranes (EMD Millipore, Billerica, MA, USA). Following blocking with 5\% non-fat milk in tris-buffered saline with $0.1 \%$ Tween 20 (TBST) for $1 \mathrm{~h}$ at room temperature, the membranes were immunoblotted overnight at $4^{\circ} \mathrm{C}$ with the following primary antibodies: Rabbit anti-GAPDH (1:10,000; cat. no. ab37168; Abcam) and rabbit anti-Pit-1 (1:2,000; cat. no. ab177147; Abcam). Following incubation with the secondary antibody [horseradish peroxidase (HRP)-conjugated goat anti rabbit IgG; 1:10,000; cat. no. as1107; Aspen Biotechnology] for $30 \mathrm{~min}$ at room temperature, the immuno-reactive signals of antibody-antigen complexes were visualized using enhanced chemiluminescence (ECL) reagents (ECL prime western blotting detection reagent; cat. no. as1059; Aspen Biotechnology). The density of each band was detected using a chemiluminescence imaging system (AlphaEaseFC software version 3.3.0; ProteinSimple, San Jose, CA, USA).

Von Kossa staining. Aortic rings in six-well plates were washed three times with PBS, then dehydrated, paraffin-embedded and cut into $4-\mu \mathrm{m}$ sections for storage. For analysis, the aortic rings were deparaffinized and processed for von Kossa staining using standard methods at room temperature. Sections were deparaffinized and rehydrated in distilled water, slides were incubated in silver nitrate solution (5\%) for $45 \mathrm{~min}$ and exposed to ultraviolet light, distilled water was used to wash the slides, slides were incubated in sodium thiosulfate solution (5\%) for $2 \mathrm{~min}$ and subsequently rinsed for $2 \mathrm{~min}$ with tap water and washed twice with distilled water. Subsequently, slides were incubated in nuclear fast red solution for $5 \mathrm{~min}$, rinsed for 2 min with tap water and washed twice with tap water. Ethanol was used to dehydrate the samples that were mounted in synthetic resin. Black or brown nodules under light microscope are considered positive staining.

Statistical analysis. All assays were performed $\geq 3$ times. Data were expressed as the mean \pm standard deviation. Statistical analyses were performed with SPSS 13.0 software (SPSS, Inc., Chicago, IL, USA). One-way analysis of variance was used to compare differences among groups with a post hoc Fisher protected least-significant difference test. Pearson's correlation coefficients were used to assess the correlations between parameters. Multivariable linear regression analyses were performed to determine the association between Ca content and other parameters. $\mathrm{P}<0.05$ was considered to indicate a statistically significant difference.

\section{Results}

Changes in VC and Pit-1 protein concentration. Representative photomicrographs of von Kossa-stained sections and the $\mathrm{Ca}$ content and Pit-1 protein expression of the aortic rings on day 14 are presented in Fig. 1 . When cultured in a medium with normal concentrations of glucose $(5.5 \mathrm{mM})$ and $\mathrm{Pi}$ (0.9 mM; CNT), no calcification occurred in the aortic rings. In addition, moderate calcification occurred in high glucose (30 mM; HG) or high Pi (2.5 mM; HPi) medium and the calcification in the HG medium was increased compared with the HPi medium. The most extensive calcification occurred in $\mathrm{HG}+\mathrm{HPi}$ (glucose $30 \mathrm{mM}+\mathrm{Pi} 2.5 \mathrm{mM}$; HGHPi) medium. Regarding calcium content and expression of Pit-1 protein, the aortic rings cultured with the various glucose and Pi concentrations exhibited the lowest level of alterations in the CNT medium, moderate alterations in the HG or HPi medium, and the greatest alterations in the HGHPi medium. Ca content and Pit-1 protein expression in the HGHPi group were significantly increased compared with the HG and HPi groups $(\mathrm{P}<0.05)$. Therefore, the combined effects of hyperglycemia and hyperphosphatemia were demonstrated on VC and Pit-1 protein expression.

Alterations in VSMC phenotypic transition. To examine potential changes in VSMC phenotypic transition, RT-qPCR analysis was used to detect the relative mRNA expression of Runx2, SM22 $\alpha$ and SM $\alpha$-actin of the aortic rings cultured with the various glucose and $\mathrm{Pi}$ concentrations on day 14 (Fig. 2). Significant downregulation of SM22 $\alpha$ and SM $\alpha$-actin and upregulation of Runx 2 were observed in the HPi, HG and HGHPi groups, compared with the CNT $(\mathrm{P}<0.05)$, and the differences were significant between the HGHPi and HPi or HG groups $(\mathrm{P}<0.05)$. The combined effects of hyperglycemia and hyperphosphatemia were also identified on the phenotypic transition of VSMCs.

Dose-dependent effect of SPL on VC and Pit-1 expression. To study the optimal serum concentrations of SPL on Pi-induced calcification with or without hyperglycemia, three different SPL concentrations were tested: Low (LS; $200 \mathrm{ng} / \mathrm{ml}$ ), medium (MS; 1,000 ng/ml) and high (HS; 5,000 ng/ml). Von Kossa-stained sections, Ca content and Pit-1 protein expression of the aortic rings on day 14 are presented in Fig. 3. The $\mathrm{HPi}$ and HGHPi groups demonstrated that the protective effects of SPL in VC and Pit-1 suppression were significantly strengthened when its concentration was increased $(\mathrm{P}<0.05)$. Therefore it was concluded that there was a dose-dependent effect of SPL on VC protecting and Pit-1 suppression of aortic rings cultured in hyperphosphatemia with or without hyperglycemia media.

Dose-dependent effect of SPL on VSMC phenotypic transition. The relative mRNA expression of Runx2, SM $22 \alpha$ and $\mathrm{SM} \alpha$-actin of the aortic rings cultured with the various glucose, Pi and SPL concentrations on day 14 were evaluated by RT-qPCR analysis (Fig. 4). The downregulation of 


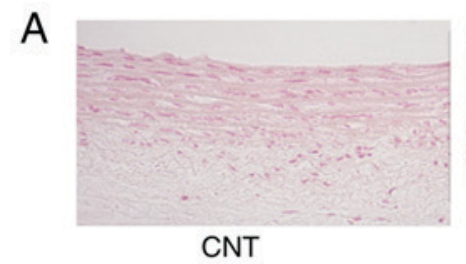

B

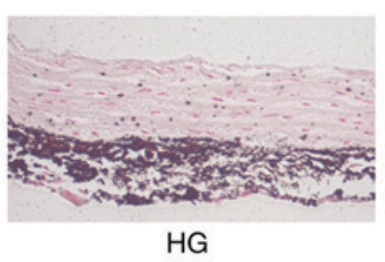

(Original magnification $\times 200)$

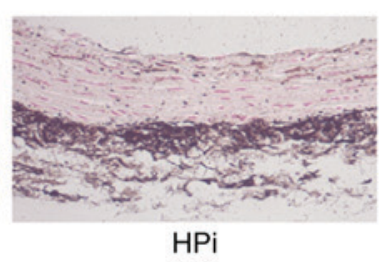

$\mathrm{HPi}$

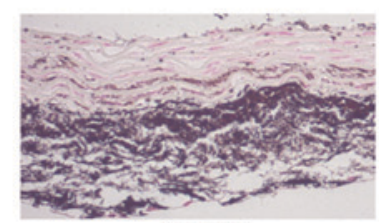

HGHPi

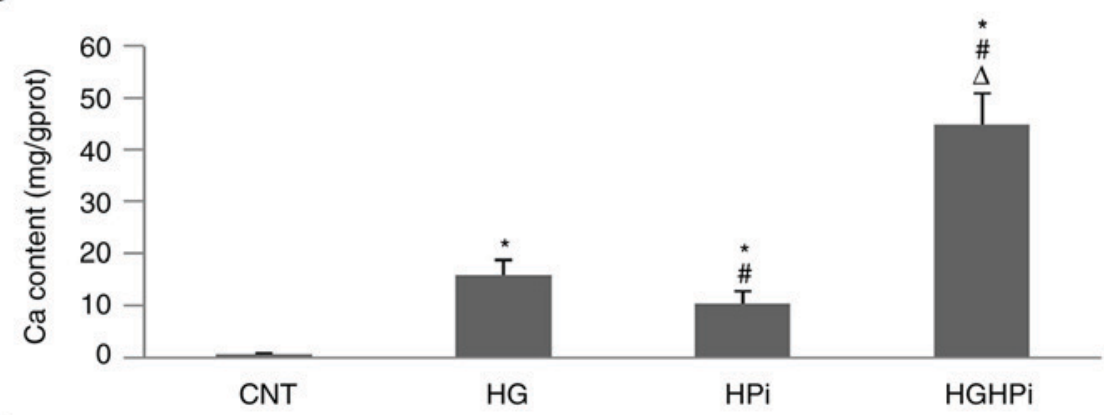

C

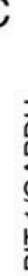

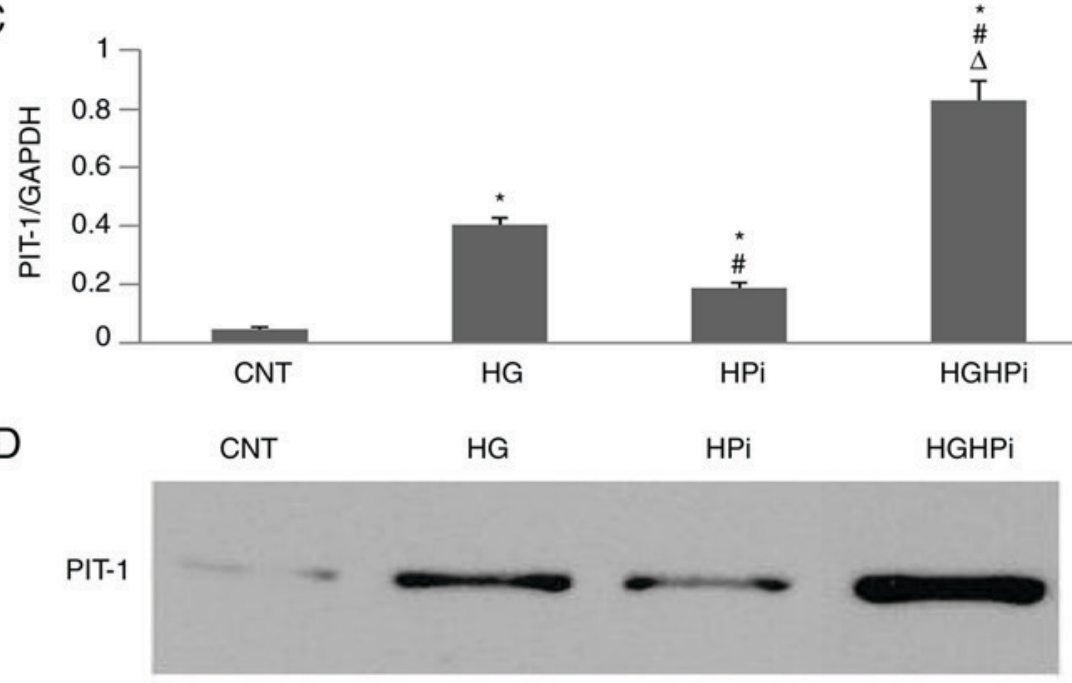

$74 \mathrm{kDa}$

GAPDH

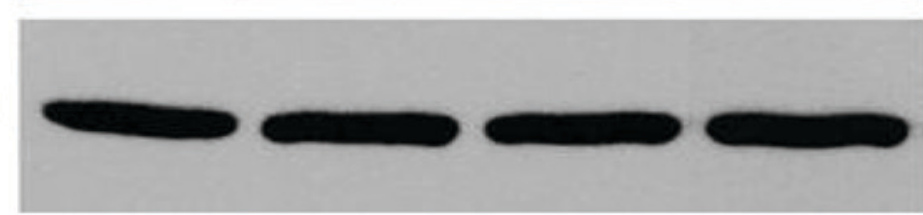

$37 \mathrm{kDa}$

Figure 1. Rat aortic rings were cultured in media with various glucose and Pi concentrations for 14 days respectively. (A) Von Kossa-stained sections (original magnification x200) exhibited no staining when cultured in CNT medium (normal concentrations: $5.5 \mathrm{mM}$ glucose, $0.9 \mathrm{mM}$ Pi). Sections exhibited moderate calcification in $\mathrm{HG}$ medium ( $30 \mathrm{mM}$ glucose, $0.9 \mathrm{mM} \mathrm{Pi}$ ) and HPi medium $(5.5 \mathrm{mM}$ glucose, $2.5 \mathrm{mM} \mathrm{Pi})$. The most extensive calcification occurred in the HGHPi medium (30 mM glucose, $2.5 \mathrm{mM} \mathrm{Pi}$ ). (B) Calcium content and, expression of (C) Pit-1 protein and (D) the western blot from the aortic rings cultured with the various glucose and Pi concentrations also demonstrated that the lowest levels of alterations occurred in the CNT medium, moderate alterations occurred in the HG or HPi medium, and the greatest alterations occurred in the HGHPi medium. Results are the average of 9 rings and represent an independent experiment ( $\mathrm{n}=9$ rings obtained from 8 rats). ${ }^{*} \mathrm{P}<0.05$ vs. CNT; ${ }^{*} \mathrm{P}<0.05$ vs. HG; ${ }^{\Delta} \mathrm{P}<0.05$ vs. HPi. CNT, control; HG, high glucose; HPi, high phosphate group; HGHPi, HG+HPi (glucose $30 \mathrm{mM}+\mathrm{Pi} 2.5 \mathrm{mM}$ ); Pit-1, type III sodium-dependent phosphate cotransporter-1.

SM22 $\alpha$ and SM $\alpha$-actin and upregulation of Runx 2 caused by hyperphosphatemia with or without hyperglycemia were significantly alleviated by SPL in a dose-dependent manner $(\mathrm{P}<0.05)$. The results indicated a dose-dependent effect of SPL on alleviating the phenotypic transition of VSMCs. However, no statistical difference between the vehicle and low dose SPL groups on $\mathrm{SM} \alpha$-actin expression was identified.

Correlations between parameters. To assess the correlations between parameters, Pearson's linear correlation analysis was used. The expression of Pit-1 relative to that of GAPDH, the fold-changes in Runx2, SM22 $\alpha$ and SM $\alpha$-actin expression, and the Ca content of the aortic rings were significantly correlated with one other $(\mathrm{P}<0.0001$; Table I). To investigate the influence of Ca content (mg/gprot), multivariable linear regression analysis was used. The dependent variable was calcium content in the aortic rings. A stepwise regression method was used to select variables. The inclusion criterion was $\alpha=0.05$ and the exclusion criterion was $\alpha=0.1$. Pit- 1 expression relative to GAPDH, Runx 2 fold-increase and SM22 $\alpha$ fold-increase were determined as factors capable of influencing $\mathrm{Ca}$ content (Table II). 

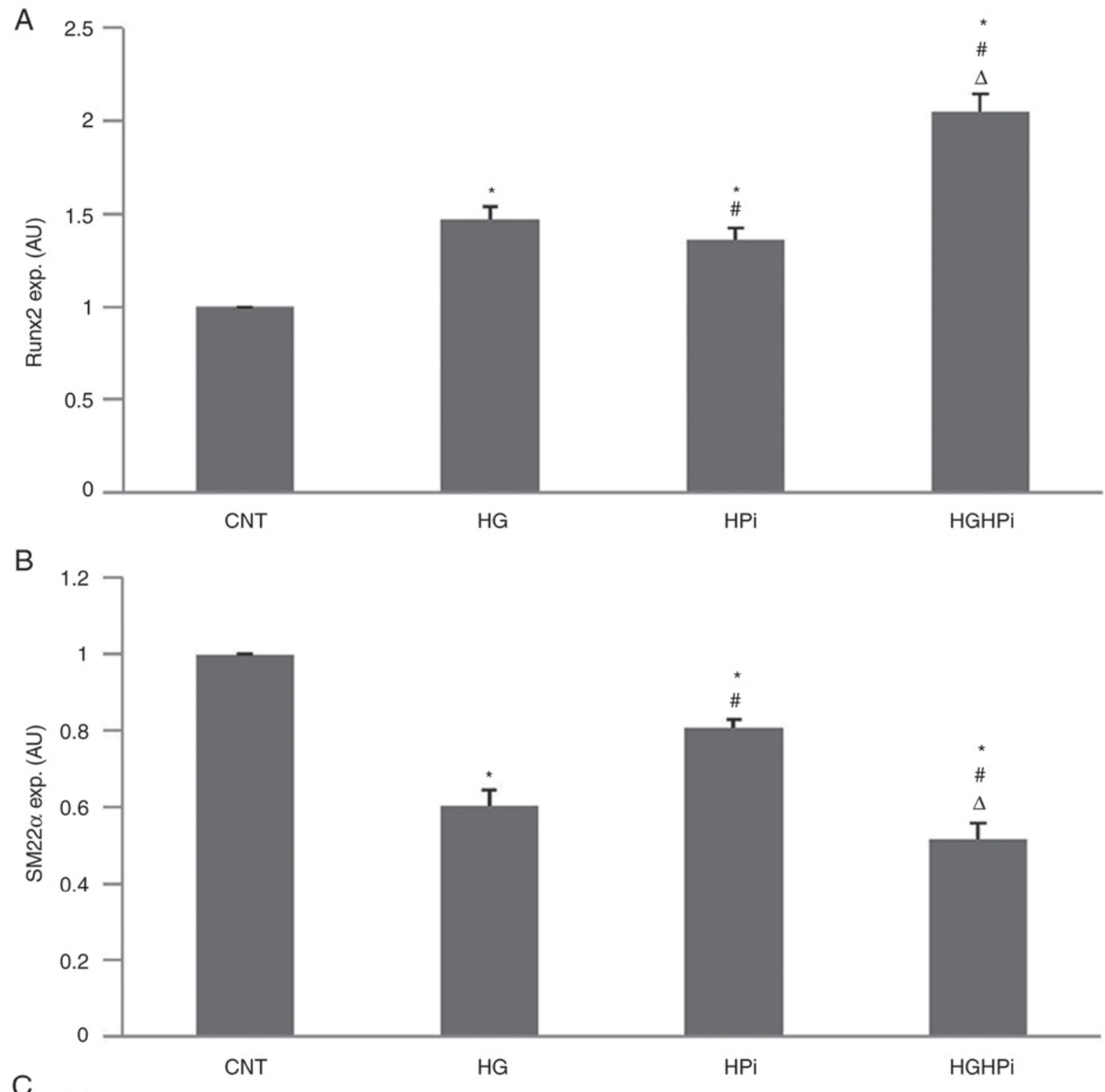

C

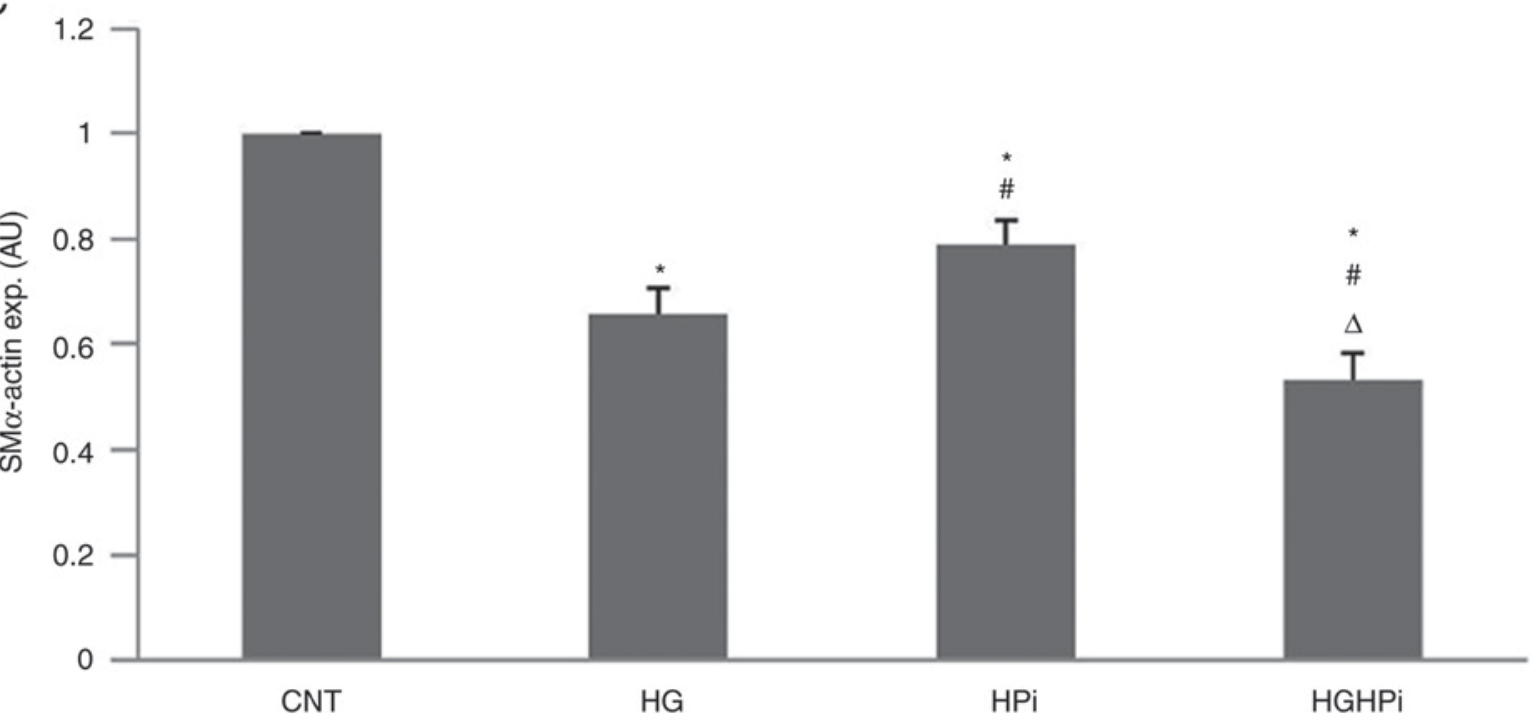

Figure 2. Rat aortic rings were cultured in media with various glucose and Pi concentrations for 14 days respectively. The relative mRNA expression levels of (A) Runx2, (B) SM22 $\alpha$ and (C) SM $\alpha$-actin evaluated by reverse transcription-quantitative polymerase chain reaction analysis. Results are the average of 9 rings and represent an independent experiment ( $\mathrm{n}=9$ rings obtained from 6 rats). CNT: $5.5 \mathrm{mM}$ glucose, $0.9 \mathrm{mM}$ Pi; HG: $30 \mathrm{mM}$ glucose, $0.9 \mathrm{mM} \mathrm{Pi}$;Pi: $5.5 \mathrm{mM}$ glucose, $2.5 \mathrm{mM}$ Pi; HGHPi: $30 \mathrm{mM}$ glucose, $2.5 \mathrm{mM}$ Pi. " $\mathrm{P}<0.05$ vs. with CNT; ${ }^{\prime} \mathrm{P}<0.05$ vs. HG; ${ }^{\wedge} \mathrm{P}<0.05$ vs. HPi. CNT, control; HG, high glucose; $\mathrm{HPi}$, high phosphate group; HGHPi, HG+HPi (glucose $30 \mathrm{mM}+\mathrm{Pi} 2.5 \mathrm{mM}$ ); Pit-1, type III sodium-dependent phosphate cotransporter-1; AU, arbitrary unit; SM, smooth; Runx2, runt-related transcription factor 2 . 
A

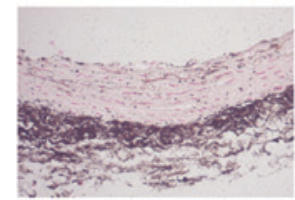

$\mathrm{HPi}$

B

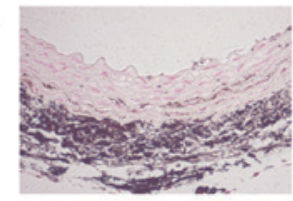

HGHPi

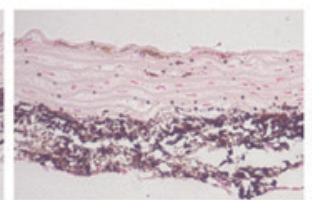

HPiLS

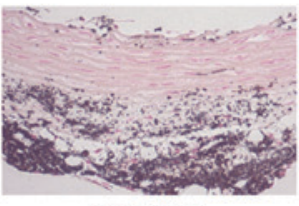

HGHPiLS

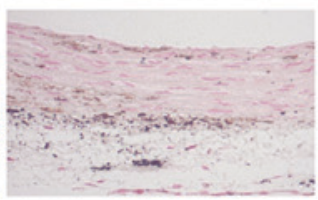

HPiMS

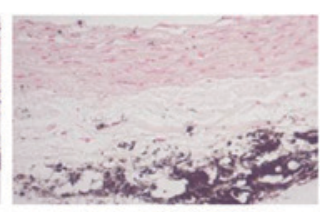

HGHPIMS

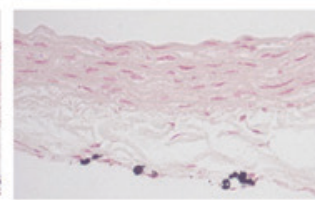

HPiHS

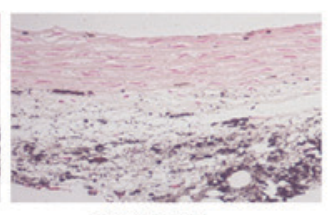

HGHPiHS

(Original magnification $\times 200)$

C

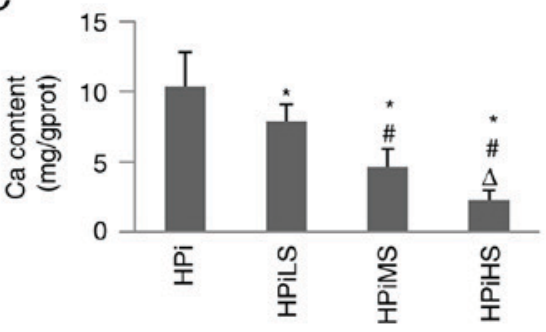

D

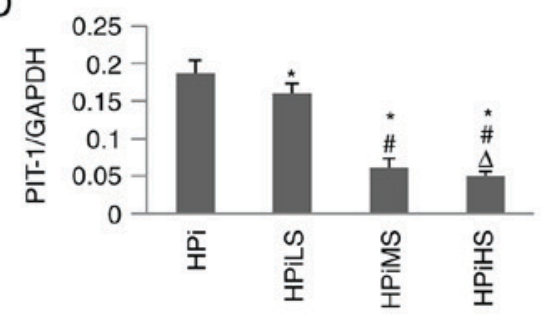

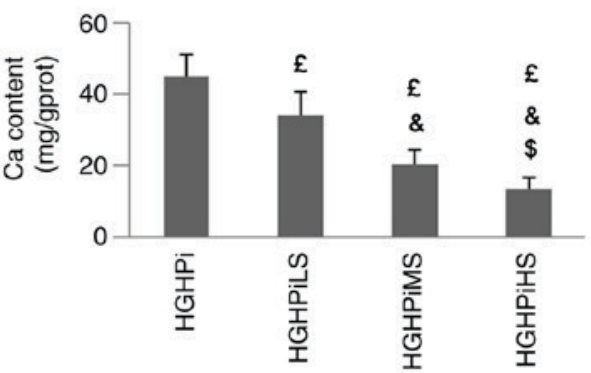

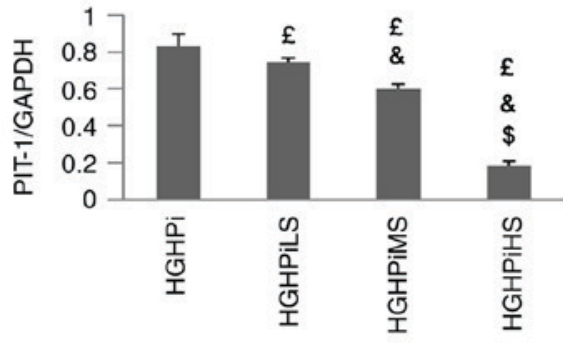

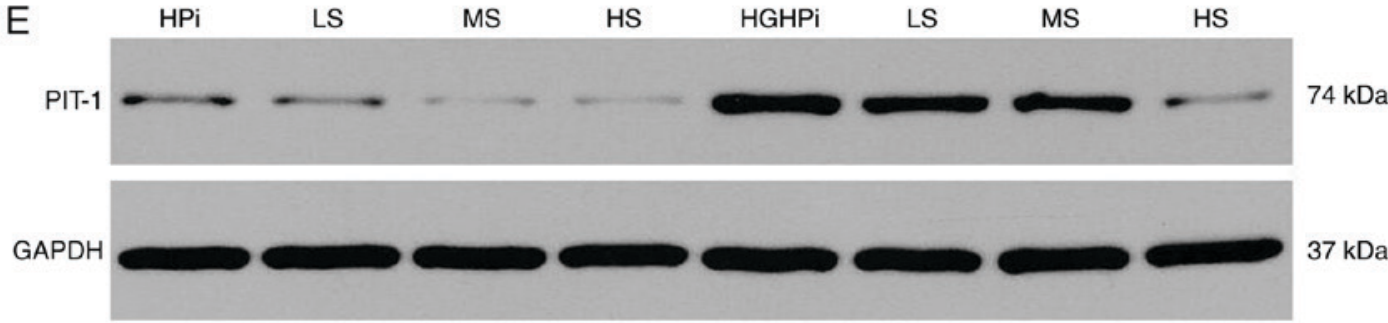

Figure 3. Rat aortic rings were cultured in $2.5 \mathrm{mM}$ Pi media with $5.5 \mathrm{mM}$ glucose (HPi) or $30 \mathrm{mM}$ glucose (HGHPi) and different concentrations of SPL $(0,200,1,000$ or $5,000 \mathrm{ng} / \mathrm{ml})$ for 14 days respectively. Von Kossa-stained sections (original magnification x200) exhibited extensive calcification when cultured in (A) HPi or (B) HGHPi medium. The calcification was gradually alleviated when the SPL concentration was increased. LS stands for low SPL concentration $(200 \mathrm{ng} / \mathrm{ml})$, MS for medium SPL concentration $(1,000 \mathrm{ng} / \mathrm{ml})$ and HS for high SPL concentration $(5,000 \mathrm{ng} / \mathrm{ml})$. (C) Calcium content and (D) expression of Pit-1 protein in aortic rings demonstrates similar results and (E) the original western blot. Results are the average of 9 rings and represent an independent experiment ( $\mathrm{n}=9$ rings obtained from 14 rats). ${ }^{*} \mathrm{P}<0.05$ vs. the HPi group; ${ }^{\#} \mathrm{P}<0.05$ vs. the HPiLS group; ${ }^{4} \mathrm{P}<0.05$ vs. the $\mathrm{HPiMS}$ group; ${ }^{\mathrm{f}} \mathrm{P}<0.05$ vs. the HGHPi group; ${ }^{\&} \mathrm{P}<0.05$ vs. the HGHPiLS group; ${ }^{\$} \mathrm{P}<0.05$ vs. the HGHPiMS group. CNT, control; HG, high glucose; HPi, high phosphate group; HGHPi, HG+HPi (glucose $30 \mathrm{mM}+\mathrm{Pi} 2.5 \mathrm{mM}$ ); Pit-1, type III sodium-dependent phosphate cotransporter-1; MS, medium spironolactone; HS, high spironolactone; LS, low spironolactone; SPL, spironolactone.

\section{Discussion}

CKD patients suffer from complications including hyperphosphatemia, anemia, hypertension, hyperglycemia and so on. It is now widely accepted that hyperphosphatemia and hyperglycemia can accelerate VC $(4,26)$, and other complications including hypercalcemia and systemic inflammation, which are also reported to be associated with VC in CKD patients $(28,29)$. Hyperphosphatemia is very common in CKD patients no matter the cause of renal function loss. The present study hypothesized that SPL may interfere with VC through Pit-1 suppression. So, hyperphosphatemia was chosen as the calcification medium and Pit-1 the object of study. The normal range of serum phosphorus level is $0.81-1.45 \mathrm{mM}$ (26), though this is elevated in CKD patients. Jono et al (30) reported that no matrix calcification occurred in human VSMCs incubated with $1.4 \mathrm{mM}$ phosphate in vitro, but dose-dependent calcification occurred when the phosphate levels were increased from 

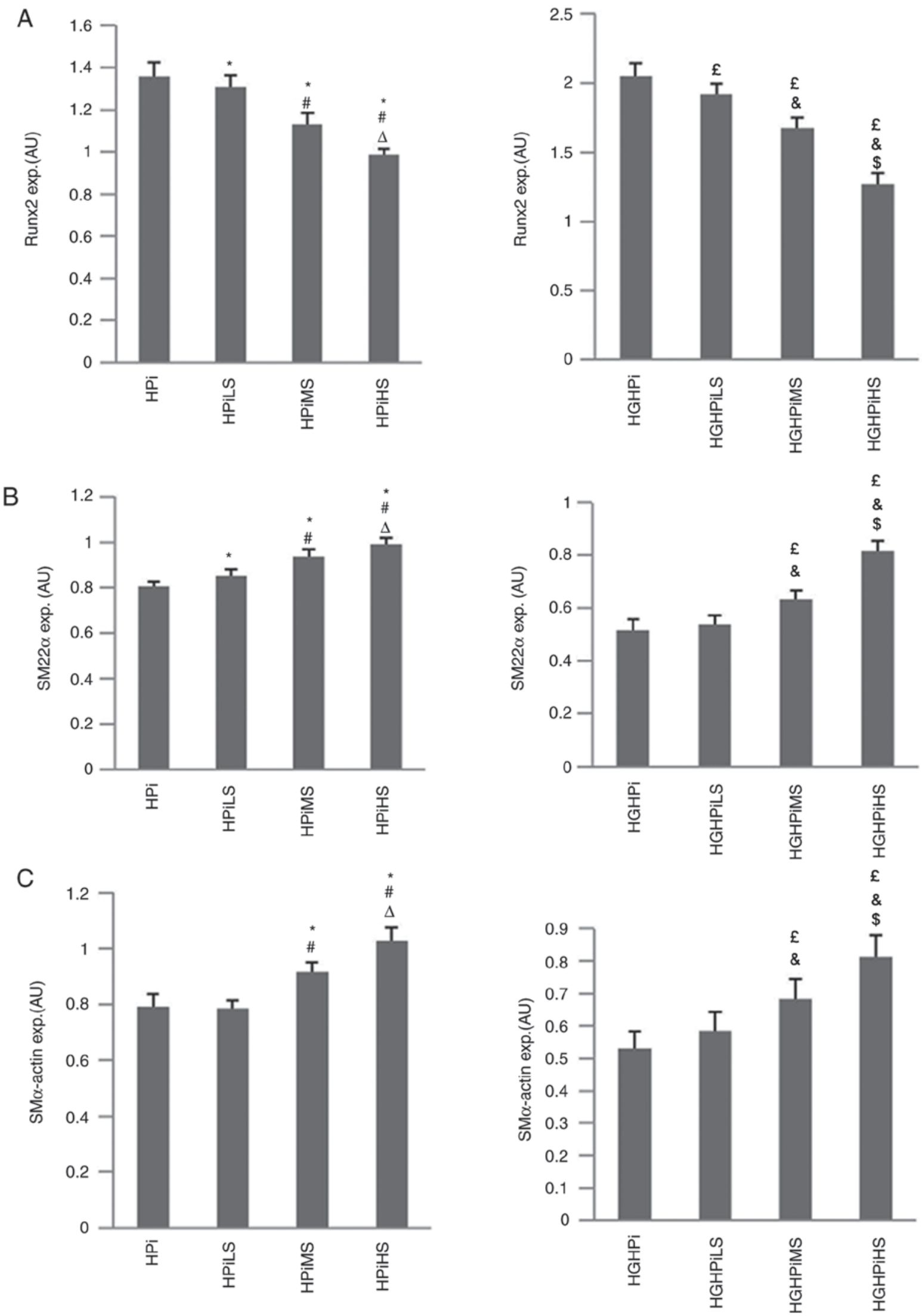

Figure 4. Rat aortic rings were cultured in $2.5 \mathrm{mM}$ Pi media with $5.5 \mathrm{mM}$ glucose (HPi) or $30 \mathrm{mM}$ glucose (HGHPi) and different concentrations of SPL $(0,200,1,000$ or $5,000 \mathrm{ng} / \mathrm{ml})$ for 14 days respectively. The relative mRNA expression levels of (A) Runx2, (B) SM22 $\alpha$ and (C) SM $\alpha$-actin evaluated by reverse transcription-quantitative polymerase chain reaction analysis. LS stands for low SPL concentration (200 ng/ml), MS for medium SPL concentration $(1,000 \mathrm{ng} / \mathrm{ml})$ and $\mathrm{HS}$ for high SPL concentration $(5,000 \mathrm{ng} / \mathrm{ml})$. Results are the average of 9 rings and represent an independent experiment $(\mathrm{n}=9$ rings obtained from 10 rats). ${ }^{\mathrm{P}}<0.05$ vs. the HPi group; ${ }^{\#} \mathrm{P}<0.05$ vs. the HPiLS group; ${ }^{\circ} \mathrm{P}<0.05$ vs. the HPiMS group; ${ }^{\mathrm{f}} \mathrm{P}<0.05$ vs. the HGHPi group; ${ }^{\text {\& }} \mathrm{P}<0.05$ vs. the HGHPiLS group; ${ }^{\mathrm{S}} \mathrm{P}<0.05$ vs. the HGHPiMS group. AU, arbitrary unit; CNT, control; $\mathrm{HG}$, high glucose; HPi, high phosphate group; $\mathrm{HGHPi}, \mathrm{HG}+\mathrm{HPi}$ (glucose $30 \mathrm{mM}+\mathrm{Pi}$ $2.5 \mathrm{mM}$ ); Pit-1, type III sodium-dependent phosphate cotransporter-1; MS, medium spironolactone; HS, high spironolactone; LS, low spironolactone; SPL, spironolactone; SM, smooth; Runx2, runt-related transcription factor 2. 
Table II. Multivariable analysis of factors associated with calcium content in the aortic rings.

\begin{tabular}{lrrc}
\hline Variable & $\begin{array}{c}\text { Parameter } \\
\text { estimate }\end{array}$ & F value & Pr>F \\
\hline Intercept & -48.07571 & 19.14 & $<.0001$ \\
PIT-1/GAPDH & 18.58513 & 7.41 & 0.0079 \\
Runx2 expansion folds & 22.49508 & 20.03 & $<.0001$ \\
SM22 $\alpha$ expansion folds & 17.12549 & 4.83 & 0.0308
\end{tabular}

Multivariable linear regression analysis was used to research the influence factors of $\mathrm{Ca}$ content (mg/gprot). The data indicate that Pit-1/GAPDH, Runx 2 expansion folds and SM22 $\alpha$ expansion folds are influence factors of Ca content. Pit-1, type III sodium-dependent phosphate cotransporter-1; SM, smooth; Runx2, runt-related transcription factor 2 .

$1.6 \mathrm{mM}$ to $3 \mathrm{mM}$. Therefore, $2.5 \mathrm{mM}$ was chosen as the high $\mathrm{Pi}$ concentration in our experiment. Due to interest in diabetic nephropathy (DN), a high glucose group (30 mM glucose) was also added. Considering the weak points of in vivo rat models, including variations in the success rate of modeling, survival rate, influence of eating activity and rate of absorption of diet/medicine, and unstable drug concentrations, ex vivo model of rat aortic tissue culture was also used, which retains the structure and matrix of a vessel and is closer to the in vivo situation than cell line cultures (28).

The present study indicated that high Pi induces the phenotypic transition and calcification of VSMCs that entails a downregulation of VSMC differentiation marker genes (SM $\alpha$-actin and SM22 $\alpha$ ) and an upregulation of osteoblast-specific genes (Runx2), which is consistent with previous studies $(10,31)$. Furthermore, it was observed that high blood glucose exhibited a similar effect and when accompanied by high $\mathrm{Pi}$, the alterations were more substantial. This contrasts with a previous study in which a hyperglycemia model was induced by streptozotocin (STZ), and the authors observed that the STZ-induced hyperglycemia was not sufficient to induce $\mathrm{VC}$ in rats in vivo (32), which has also been reported by another study (33). Therefore, it was hypothesized that STZ may intervene in the process of $\mathrm{VC}$, explaining the discrepancy between results of the present study and the previous findings. Nonetheless, the underlying mechanism requires further assessment. From another perspective, due to the complex mechanisms of $\mathrm{VC}$, the authors insist on their premise that the experimental model should be as simple as possible to avoid the potential impact from unassociated components. Previously, human aortic smooth muscle cells were cultured in hyperglycemic and hyperphosphatemic media, and the combined effects of hyperphosphatemia and hyperglycemia were also observed on human aortic smooth muscle cell calcification (34). Regarding the above-mentioned results, it was concluded that there were combined effects of hyperglycemia and hyperphosphatemia on VSMC calcification, and it is considered to be a key explanation for why ESRD patients with diabetes mellitus exhibted shorter survival times/higher mortality rate (35-37). In addition, it 
was noticed that calcification in $30 \mathrm{mM}$ glucose (HG) was more significant than in $2.5 \mathrm{mM} \mathrm{Pi}$. Despite having control of serum phosphorus level, VC may still progress seriously if other complications that can contribute to $\mathrm{VC}$ are not well managed. Therefore, with respect to vascular protection strategies for CKD patients, all associated complications should be focused on; in other words, individual therapy may be required for each patient. This is another reason why the two current CKD models for VC, the adenine-induced model and the partial nephrectomy model, are considered to be limited.

Pit-1, a type III NaPi cotransporter, is the predominant $\mathrm{NaPi}$ cotransporter in human VSMCs, and is required for phosphate-induced calcification of human VSMCs (14). Previous studies reported that knockdown of Pit-1 expression by small interfering RNA inhibited sodium-dependent phosphate uptake as well as phosphate-dependent SMC calcification, and restoration of phosphate uptake by overexpression of Pit-1 in Pit-1-deficient cells rescued calcification (14-16). Phosphonoformic acid, a competitive inhibitor of NaPi transport, could inhibit VC which was dependent on the activity of Pit-1 or induced expression of Pit-1 (38-40). In osteoblast-like cells, Pit-1 expression increases during differentiation and correlates with mineralization (41). These findings collectively indicate that Pit-1 regulation serves a pivotal role in the pathogenesis of VC in CKD. In the present study, a close association between Pit-1 protein level and the change of phenotypic genes (Runx2, SM22 $\alpha$ and SM $\alpha$-actin) as well as the calcium content of aortic rings cultured in hyperphosphatemia with or without hyperglycemia media, which proved that Pit-1 protein can induce VC through regulating the phenotypic transition of vascular smooth muscle cells to osteoblast-like cells. Therefore, the Pit-1 protein level was considered to be a novel index for evaluating the magnitude of $\mathrm{VC}$ in $\mathrm{CKD}$ patients. Further studies are needed to determine the precise range of Pit-1 protein levels in healthy individuals as well as CKD patients.

VSMCs express MR, and aldosterone is known to promote VC $(21,22,42)$. Aldosterone dose-dependently upregulates Pit-1 expression and potentiates the effects of phosphate on Pit-1 expression $(15,43)$. SPL, an MR antagonist, has been demonstrated to improve cardiovascular outcomes in patients with heart disease (17-20). Previous studies suggest that SPL can attenuate $\mathrm{VC}$ and kidney damage in adenine-induced uremic rats and klotho-hypomorphic mice $(24,43)$; however, the underlying mechanisms and the effective dose are yet to be determined. Tatsumoto et al (24) administered 50 and $100 \mathrm{mg} \cdot \mathrm{kg}^{-1} \cdot \mathrm{day}^{-1} \mathrm{SPL}$ orally for 8 weeks to adenine-induced uremic rats, and protective effects on VC occurred at the two doses, and it seemed the greater the dose the better effect. Clearly, even the $50 \mathrm{mg} \cdot \mathrm{kg}^{-1} \cdot \mathrm{day}^{-1} \mathrm{SPL}$ dose is too high for human beings and may cause a number of side effects including hyperkalemia, which is considered critical in CKD, especially in ESRD patients. Early research on the pharmacokinetics of SPL indicated that SPL is partially metabolized into canrenone, $7 \alpha$-thiomethylspirolactone and $6 \beta$-hydroxy-7 $\alpha$-thiomethylspirolactone, while the remaining SPL remains detectable in the serum up to $8 \mathrm{~h}$ following oral administration $(44,45)$. Several hours following administration of a single oral dose of $200 \mathrm{mg}$
SPL in men weighing $65-87 \mathrm{~kg}$ (mean dose $2.6 \mathrm{mg} \cdot \mathrm{kg}^{-1}$ ), the total serum concentration of SPL and its metabolites reportedly reaches $1,000 \mathrm{ng} / \mathrm{ml}$ (45), and a similar result has been reported in another study (46). Nonetheless, the routine dose of SPL for patients with CKD is $25 \mathrm{mg}$ once daily (47). It was hypothesized that SPL may interfere with VC through Pit-1 suppression in a dose-dependent manner, therefore the present study was initiated and $200 \mathrm{ng} / \mathrm{ml} \mathrm{SPL}$ was set as the low dose, $1,000 \mathrm{ng} / \mathrm{ml}$ as the medium dose and 5,000 ng/ml as the high dose. The results of the present study demonstrated that SPL dose-dependently alleviates the progression of VC by suppressing the expression of Pit-1 and preventing the phenotypic transition of VSMCs, which proved the authors' hypothesis. Previously, a protective effect of SPL on insulin resistance in CKD patients has been reported (48), which indicated that SPL may provide other clinical benefits besides cardiovascular protection. Therefore, SPL is regarded as a very promising agent for the treatment of CKD patients, including those with DN, and the dose used in clinical practice could be properly increased. In consideration of the side effects of SPL, additional studies are required to clarify the mechanisms and appropriate dose and the precise chemical compositions of SPL and its metabolites in more depth.

Although the experimental model used in the present study is seemingly closer to the in vivo situation than cell line cultures and to the clinical situation than the two current VC models in CKD rats, it is not completely the same condition as that in vivo.

This article to our knowledge is the first report on the effective serum concentrations of SPL capable of protecting VSMCs from calcification by suppressing the phenotypic transition of VSMCs through downregulation of Pit-1, and provides the first experimental evidence for the combined effects of hyperglycemia and hyperphosphatemia on VC of aortic rings. SPL should be regarded as a highly promising agent for the treatment of CKD patients including those with $\mathrm{DN}$, and the dose used in clinical practice could be properly increased. Furthermore, the Pit-1 protein level may be a novel index for evaluating the magnitude of $\mathrm{VC}$ in $\mathrm{CKD}$ patients. A number of further studies in experimental models and humans in order to better replicate the condition of CKD patients are needed to confirm the full mechanisms underlying $\mathrm{VC}$, and to identify the most appropriate dose as well as the precise chemical compositions of SPL and its metabolites.

\section{Acknowledgements}

The authors would like to thank Professor Xicheng Hong [MacroStat (China) Clinical Research Co., Ltd. Wuhan, China] for his assistance with the data analysis.

\section{Funding}

The present study was partially supported by the Jingmen City Science and Technology Project (grant no. 2018YFYB023).

\section{Availability of data and materials}

All data generated and analyzed during the current study are available from the corresponding author on reasonable request. 


\section{Authors' contributions}

All authors conceived and designed the research. PW and ZQ performed the experiments and drafted the manuscript. DP analyzed the data and revised the manuscript. DL and WC interpreted the data and provided discussion on the manuscript. All authors read and approved the final manuscript.

\section{Ethics approval and consent to participate}

Ethical approval was granted by the Ethical Committee of the First People's Hospital of Jingmen and the study protocol conformed to the National Institute of Health guidelines for the care and use of laboratory animals.

\section{Patient consent for publication}

Not applicable.

\section{Competing interests}

The authors declare that they have no competing interests.

\section{References}

1. Blacher J, Guerin AP, Pannier B, Marchais SJ and London GM: Arterial calcification, arterial stiffness, and cardiovascular risk in end-stage renal disease. Hypertension 38: 938-942, 2001.

2. Ohya M, Otain H, Kimura K, Saika Y, Fujii R, Yukawa S and Shigematsu T: Vascular calcification estimated by aortic calcification area index is significant predictive parameter of cardiovascular mortality in hemodialysis patients. Clin Exp Nephrol 15: 877-883, 2011.

3. London GM, Guérin AP, Marchais SJ, Métivier F, Pannier B and Adda H: Arterial media calcification in end-stage renal disease: Impact on all-cause and cardiovascular mortality. Nephrol Dial Transplant 18: 1731-1740, 2003.

4. Górriz JL, Molina P, Cerverón MJ, Vila R, Bover J, Nieto J, Barril G, Martínez-Castelao A, Fernández E, Escudero V, et al: Vascular calcification in patients with nondialysis CKD over 3 years. Clin J Am Soc Nephrol 10: 654-666, 2015.

5. Hruska KA, Mathew S, Lund R, Qiu P and Pratt R: Hyperphosphatemia of chronic kidney disease. Kidney Int 74: 148-157, 2008.

6. Demer LL and Tintut Y: Vascular calcification: Pathobiology of a multifaceted disease. Circulation 117: 2938-2948, 2008 .

7. Giachelli CM: Vascular calcification mechanisms. J Am Soc Nephrol 15: 2959-2964, 2004.

8. Mizobuchi M, Tower D and Slatopolsky E: Vascular calcification: The killer of patients with chronic kidney disease. J Am Soc Nephrol 20: 1453-1464, 2009.

9. Shanahan CM, Crouthamel MH, Kapustin A and Giachelli CM: Arterial calcification in chronic kidney disease: Key roles for calcium and phosphate. Circ Res 109: 697-711, 2011.

10. Steitz SA, Speer MY, Curinga G, Yang HY, Haynes P, Aebersold R, Schinke T, Karsenty G and Giachelli CM: Smooth muscle cell phenotypic transition associated with calcification: Upregulation of Cbf $\alpha 1$ and downregulation of smooth muscle lineage markers. Circ Res 89: 1147-1154, 2001.

11. Speer MY, Li X, Hiremath PG and Giachelli CM: Runx2/Cbfa1, but not loss of myocardin, is required for smooth muscle cell lineage reprogramming toward osteochondrogenesis. J Cell Biochem 110: 935-947, 2010.

12. Zhang J,Zheng B,Zhou PP,Zhang RN, He M, Yang Z and Wen JK: Vascular calcification is coupled with phenotypic conversion of vascular smooth muscle cells through Klf5-mediated transactivation of the Runx2 promoter. Biosci Rep 34: e00148, 2014.

13. Liao L, Zhuang X, Li W, Su Q, Zhao J and Liu Y: Polysaccharide from Fuzi protects against Ox-LDL-induced calcification of human vascular smooth muscle cells by increasing autophagic activity. Mol Med Rep 17: 5109-5115, 2018.
14. Miyamoto K, Haito-sugino S, Kuwahara S, Ohi A, Nomura K, Ito M, Kuwahata M, Kido S, Tatsumi S, Kaneko I and Segawa H: Sodium-dependent phosphate cotransporters: Lessons from gene knockout and mutation studies. J Pharm Sci 100: 3719-3730, 2011.

15. Li X, Yang HY and Giachelli CM: Role of the sodium-dependent phosphate cotransporter, Pit-1, in vascular smooth muscle cell calcification. Circ Res 98: 905-912, 2006.

16. Lau WL, Festing MH and Giachelli CM: Phosphate and vascular calcification: Emerging role of the sodium-dependent phosphate co-transporter PiT-1. Thromb Haemost 104: 464-470, 2010.

17. Pitt B, Zannad F, Remme WJ, Cody R, Castaigne A, Perez A, Palensky $\mathrm{J}$ and Wittes $\mathrm{J}$ : The effect of spironolactone on morbidity and mortality in patients with severe heart failure. Randomized aldactone evaluation study investigators. N Engl J Med 341: 709-717, 1999.

18. Vizzardi E, D'Aloia A, Giubbini R, Bordonali T, Bugatti S, Pezzali N, Romeo A, Dei Cas A, Metra M and Dei Cas L: Effect of spironolactone on left ventricular ejection fraction and volumes in patients with class I or II heart failure. Am J Cardiol 106: 1292-1296, 2010.

19. Brief M and Schiffrin EL: Vascular actions of aldosterone. J Vasc Res 50: 89-99, 2013.

20. McCurley A and Jaffe IZ: Mineralocorticoid receptors in vascular function and disease. Mol Cell Endocrinol 350: 256-265, 2012

21. Wu SY, Yu YR, Cai Y, Jia LX, Wang X, Xiao CS, Tang CS and Qi YF: Endogenous aldosterone is involved in vascular calcification in rat. Exp Biol Med (Maywood) 237: 31-37, 2012.

22. Jaffe IZ, Tintut Y, Newfell BG, Demer LL and Mendelsohn ME: Mineralocorticoid receptor activation promotes vascular cell calcification. Arterioscler Thromb Vasc Biol 27: 799-805, 2007.

23. Nitta K, Akiba T and Nihei H: Aldosterone blockade and vascular calcification in hemodialysis patients. Am J Med 115: $250,2003$.

24. Tatsumoto N, Yamada S, Tokumoto M, Eriguchi M, Noguchi H, Torisu K, Tsuruya K and Kitazono T: Spironolactone ameliorates arterial medial calcification in uremic rats: The roll of mineralocorticoid receptor signaling in vascular calcification. Am J Physiol Renal Physiol 309: F967-F999, 2015.

25. Yokozawa T, Zheng PD, Oura H and Koizumi F: Animal model of adenine-induced chronic renal failure in rats. Nephron 44: 230-234, 1986.

26. Andrassy KM: Comments on 'KDIGO 2012 clinical practice guideline for the evaluation and management of chronic kidney disease'. Kidney Int 84: 622-623, 2013.

27. Livak KJ and Schmittgen TD: Analysis of relative gene expression data using real-time quantitative PCR and the 2(-Delta Delta C(T)) Method. Methods 25: 402-408, 2001.

28. Masumoto A, Sonou T, Ohya M, Yashiro M, Nakashima Y, Okuda K, Iwashita Y, Mima T, Negi S and Shigematsu T: Calcium overload accelerates phosphate-induced vascular calcification via Pit-1, but not the calcium-sensing receptor. J Atheroscler Thromb 24: 716-724, 2017.

29. Hwang IC, Park HE, Kim HL, Kim HM, Park JB, Yoon YE, Lee SP, Kim HK, Cho GY, Sohn DW and Kim YJ: Systemic inflammation is associated with coronary artery calcification and all-cause mortality in chronic kidney disease. Circ J 80: 1644-1652, 2016

30. Jono S, McKee MD, Murry CE, Shioi A, Nishizawa Y, Mori K, Morii $\mathrm{H}$ and Giachelli CM: Phosphate regulation of vascular smooth muscle cell calcification. Circ Res 87: E10-E17, 2000.

31. Yoshida T, Yamashita M and Hayashi M: Kruppel-like factor 4 contributes to high phosphate-induced phenotypic switching of vascular smooth muscle cells into osteogenic cells. J Biol Chem 287: 25706-25714, 2012.

32. Yoshida T, Yamashita M, Horimai C and Hayashi M: High glucose concentration does not modulate the formation of arterial medial calcification in experimental uremic rats. J Vasc Res 50: 512-520, 2013

33. Ren X, Wei Q, Shao H, Sun Z and Liu N: A rat model of diabetic artery calcification. J Endocrinol Invest 35: 497-503, 2012.

34. Wang P, Zhou P, Chen W and Peng D: Combined effects of hyperphosphatemia and hyperglycemia on the calcification of cultured human aortic smooth muscle cells. Exp Ther Med 17: 863-868, 2019.

35. Jardine MJ, Hata J, Woodward M, Perkovic V, Ninomiya T, Arima H, Zoungas S, Cass A, Patel A, Marre M, et al: Prediction of kidney-related outcomes in patients with type 2 diabetes. Am J Kidney Dis 60: 770-778, 2012. 
36. Leavitt BJ, Sheppard L, Maloney C, Clough RA, Braxton JH, Charlesworth DC, Weintraub RM, Hernandez F, Olmstead EM, Nugent WC, et al: Effects of diabetes and associated conditions on long-term survival after coronary artery bypass graft surgery. Circulation 110 (11 suppl 1): II41-II44, 2004.

37. Wan EYF, Fong DYT, Fung CSC, Yu EYT, Chin WY, Chan AKC and Lam CLK: Prediction of new onset of end stage renal disease in Chinese patients with type 2 diabetes mellitus-a population-based retrospective cohort study. BMC Nephrol 18: 257, 2017.

38. Yang H, Curinga G and Giachelli CM: Elevated extracellular calcium levels induce smooth muscle cell matrix mineralization in vitro. Kidney Int 66: 2293-2299, 2004.

39. Villa-Bellosta R and Sorribas V: Phosphonoformic acid prevents vascular smooth muscle cell calcification by inhibiting calcium-phosphate deposition. Arterioscler Thromb Vasc Biol 29: 761-766, 1009.

40. Akiyoshi T, Ota H, Iijima K, Son BK, Kahyo T, Setou M, Ogawa S, Ouchi Y and Akishita M: A novel organ culture model of aorta for vascular calcification. Atherosclerosis 244: 51-58, 2016.

41. Suzuki A, Ghayor C, Guicheux J, Magne D, Quillard S, Kakita A, Ono Y, Miura Y, Oiso Y, Itoh M and Caverzasio J: Enhanced expression of the inorganic phosphate transporter Pit-1 is involved in BMP-2-induced matrix mineralization in osteoblast-like cells J Bone Miner Res 21: 674-683, 2006.

42. Jaffe IZ and Mendelsohn ME: Angiotensin II and aldosterone regulate gene transcription via functional mineralocortocoid receptors in human coronary artery smooth muscle cells. Circ Res 96: 643-650, 2005.

43. Voelk1 J, Alesutan I, Leibrock CB, Quintanilla-Martinez L, Kuhn V, Feger M, Mia S, Ahmed MS, Rosenblatt KP, Kuro-O M and Lang F: Spironolactone ameliorates PIT1-dependent vascular osteoinduction in klotho-hypomorphic mice. J Clin Invest 123: 812-822, 2013.

44. Kojima K, Yamamoto $\mathrm{K}$, Fujioka $\mathrm{H}$ and Kaneko $\mathrm{H}$ : Pharmacokinetics of spironolactone and potassium canrenoate in humans. J Pharmacobiodyn 8: 161-166, 1985.
45. Overdiek HW, Hermens WA and Merkus FW: New insights into the pharmacokinetics of spironolactone. Clin Pharmacol Ther 38: 469-474, 1985.

46. Terai I, Yamano K, Ichihara N, Arai J and Kobayashi K: Influence of spironolactone on neonatal screening for congenital adrenal hyperplasia. Arch Dis Child Fetal Neonatal Ed 81: F179-F183, 1999.

47. Hayer MK, Edwards NC, Slinn G, Moody WE, Steeds RP, Ferro CJ, Price AM, Andujar C, Dutton M, Webster R, et al: A randomized, multicenter, open-label, blinded end point trial comparing the effects of spironolactone to chlorthalidone on left ventricular mass in patients with early-stage chronic kidney disease: Rationale and design of the SPIRO-CKD trial. Am Heart J 191: 37-46, 2017.

48. Hosoya K, Minakuchi H, Wakino S, Fujimura K, Hasegawa K, Komatsu M, Yoshifuji A, Futatsugi K, Shinozuka K, Washida N, et al: Insulin resistance in chronic kidney disease is ameliorated by spironolactone in rats and humans. Kidney Int 87: 749-760, 2015.

This work is licensed under a Creative Commons Attribution-NonCommercial-NoDerivatives 4.0 International (CC BY-NC-ND 4.0) License. 